\title{
PACATAL * IN CARDIO-PULMONARY SURGERY
}

\author{
J.-P. DEChÊNE, M.D. †
}

IN THEIR RESEARCH on the phenothiazine derivatives, workers have endeavoured to develop substances of greater potency and less toxicity. One result of such pharmacological researches was the introduction of Pacatal in Germany by Nieschulz et al., in 1954 (1). Since then, its value as a potent ataraxic (that is, a quieting drug that relieves the symptoms of emotional and mental perturbation characterized by agitation, insomnia and preoperative anxiety) has definitely been established. In cardio-pulmonary surgery, Pacatal has also been described as an intravascular anaesthetic of the heart $(2-5)$, and it is reported to prevent or favourably influence cardiac arrhythmias in thoracic surgery. Gifted with such properties, this new ataraxic, Pacatal, deserved more exhaustive studies, experimentally on dogs as well as clinically on man. Consequently, this paper presents the results of five hundred different observations made on fifty dogs and a hundred cases of thoracic surgery on man.

\section{Chemistry and Supply}

Pacatal (N-methylpiperidyl-(3)-methyl phenothiazine) is a synthetic compound. It is available in 25 and $50 \mathrm{mg}$. tablets in the form of hydrochloride, for oral administration, and in $2 \mathrm{cc}$. ampoules ( $25 \mathrm{mg}$. per $\mathrm{cc}$ ) and in the form of the more soluble acetate, for parenteral use.

\section{Toxicity}

According to experiments made by other workers (1), in an exhaustive study on the chronic toxicity of Pacatal, darly doses of $5 \mathrm{mg} . / \mathrm{kg}$. during two months, did not modify the blood formula of dogs (red and white blood count and haemoglobin). Furthermore, repeated injections of the useful dose of Pacatal are given to dogs without noticeable toxic effects.

\section{PaCatal in Experumental Cardiac Surgery}

For this study, we drew on a pool of fifty dogs, and experiments were conducted, in fifty sessions during which five hundred observations were recorded under the following headings:

(1) $\mathrm{O}_{2}$ consumption per minute

(2) Temperature

(3) Femoral blood pressure

(4) Electrocárdiography

(5) Electromanometry

(6) Pulmonary ventilation

(7) Blood constituents
(8) Cardiac output

(9) Sedative and potentiating effect

(10) Antifibrillating effect in hypothermia

(11) Anti-swelling action

(12) Action on syrnpathetic and parasympathetic

"Pacatal ampoules and tablets necessary for this study have been graciously furnshed by Warner-Lambert Canada Limited.

†Laval Hospital, Ste-Foy, Québec. 
The fifty sessions consisted mostly of heart surgery, such as the Blalock operation, the production of mitral insufficiency, and the combined production and repair of inter-auricular defects (gross method).

\section{Anaesthetic Technique}

Before discussing the results of these different studies, let us specify that most of these dogs weighed 30 to $40 \mathrm{~kg}$., and that Pacatal was given on the basis of $5 \mathrm{mg}$. $/ \mathrm{kg}$. body weight either orally or parenterally.

The dogs were all anaesthetized in the same fashion. After a premedication of 'morphine and Pacatal, anaesthesia is induced with sodium pentobarbital I.V., 25 to $30 \mathrm{mg}$. $/ \mathrm{kg}$. body weight. As soon as the dogs were unconscious, they were intubated with a catheter equipped with an inflated cuff and pure oxygen was given. At the opening of the thorax respiration was controlled by a spiropulsator with positive pressure.

\section{Discussion}

Generally speaking, it will appear that the resulting experimental data are consistent with those of other pioneer workers on Pacatal (9).

(1) $\mathrm{O}_{2}$ consumption per minute. There were 42 observations made on 24 dogs in the course of 25 experimental sessions, one of them being used at two sessions:

$\begin{array}{cccc}\begin{array}{c}\text { No. of } \\ \text { sessions }\end{array} & \begin{array}{c}\text { No. of } \\ \text { dogs }\end{array} & \begin{array}{c}\text { No. of readings } \\ \text { each }\end{array} & \begin{array}{c}\text { No. of } \\ \text { observations }\end{array} \\ 10 & 10 & 1 & 10 \\ 12 & 11 & 2 & 22 \\ 2 & 2 & 3 & 6 \\ 1 & 1 & 4 & 4 \\ \overline{25} & 24 & & 42\end{array}$

Pacatal was found to exercise a minimal effect on the basal metabolism because there was only the slight decrease of 10 per cent and that in only 75 per cent of the cases.

(2) Body temperature. In 20 sessions on 20 different dogs 70 observations on possible temperature variations were made.

$\begin{array}{ccc}\begin{array}{c}\text { No. of dogs } \\ \text { and sessions }\end{array} & \begin{array}{c}\text { No. of readings } \\ \text { each }\end{array} & \begin{array}{c}\text { No. of } \\ \text { observations }\end{array} \\ 4 & 1 & 4 \\ 3 & 2 & 6 \\ 6 & 3 & 18 \\ 7 & 6 & 42 \\ 20 & & 70\end{array}$

The antipyretic properties of Pacatal are nil and there was no modification of the thermal curve during the interventions other than the expected slight hypothermia of a few degrees due to anaesthesia and thoracotomy. 
(3) Femoral blood pressure. The hypotensive effect of Pacatal is relatively weak. Only in large doses, such as $20 \mathrm{mg}$. $\mathrm{kg}$. body weight intravenously does it bring about a noticeable but fleeting decrease in the dog's blood pressure. In the course of continuous recording of femoral blood pressure a clecrease of about $5-10 \mathrm{~mm}$. $\mathrm{Hg}$ only is noticed.

$\begin{array}{ccc}\begin{array}{c}\text { No of dogs } \\ \text { and sessions }\end{array} & \begin{array}{c}\text { No of readings } \\ \text { each }\end{array} & \begin{array}{c}\text { No. of } \\ \text { observations }\end{array} \\ 3 & 1 & 3 \\ 6 & 2 & 12 \\ 3 & 3 & 9 \\ \overline{12} & & -24\end{array}$

(4) Electrocardiography and antifibrillating effect. During experimental cardiac surgery the electrocardiograph remained stable in most cases when Pacatal was used.

\begin{tabular}{ccc}
$\begin{array}{c}\text { No of dogs } \\
\text { and sessions }\end{array}$ & $\begin{array}{c}\text { No. of readings } \\
\text { each }\end{array}$ & $\begin{array}{c}\text { No of } \\
\text { observations }\end{array}$ \\
5 & 1 & 5 \\
2 & 2 & 4 \\
7 & 3 & 21 \\
1 & 4 & 4 \\
3 & 5 & 15 \\
2 & 6 & 12 \\
1 & 9 & 9 \\
1 & 10 & 10 \\
1 & 12 & 12 \\
1 & 13 & 13 \\
1 & 26 & 26 \\
\hline 25 & & 131
\end{tabular}

A few dogs showed readily reversible minor alterations and an incidence of only 9.8 per cent of ventricular fibrillation occurred in this series as compared to 50 per cent in a previous series (6) when Pacatal was not used. In provoked hypothermia, Pacatal made it possible to apply vascular clamps for 22 minutes at $28^{\circ} \mathrm{C}$. without precipitating fibrillation.

A refinement in evaluating the epicardial and endocardial excitability at the ventricular and auricular levels was made possible by scheduling a series of seven tests: (1) pressure under the axial edge of the left auricle, at the emergence level of the left coronary artery, (2) pressure on the medial edge of the right auricle, near the orifice of the superior vena cava; (3) pressure on the trunk of the left auriculo-ventricular artery, distal to the 2nd or 3rd collateral; (4) pressure applied with instruments on the posterior surface of the heart behind the apex, (5) pressure with the tip of the index finger across the infundibulum of the ventricle, on the anterior papillary muscle of the tricuspid, (6) the invagination of the index finger, forcing back the left auricle into the mitral orifice, partially blocking it, and into the left ventricular cavity itself; (7) the invagination of the index in the left ventricle with the left hand exerting counter-pressure either on the thoracic wall or on the right cardiac surface. 
On dogs prepared with Pacatal ( $5 \mathrm{mg} . / \mathrm{kg}$. body wt.) each test was executed while recording with an electrocardiograph. Presently, certain alterations of conduction and rhythm occurred, but contrary to what happened in the absence of Pacatal (11), when the cardiac excitement cesised, the return to normal tracings on the electrocardiograph was immediate. Thus, the great protection of Pacatal was demonstrated in permitting such rapid reappearance of the sinus rhythm after these surgical manœuvres of cardiac irritation and in hindering the appearance of prolonged anomalies of conduction and rhythm such as cardiac blockage and ventricular fibrillation Also, with Pacatal, the galvanic and faradic excitement of the heart did not produce prolonged abnormal patterns of cardiac rhythm or conduction and the sinus rhythm always reappeared once the excitement was over. The authors $(2-5)$, therefore, have reasons for describing the action of Pacatal as that of an intravascular anaesthesia of the heart. However, in the course of certain surgical manœeuvres (e.g., the production and repair of an inter-auricular communication (Gross method)) Pacatal does not appear to protect the heart from all reflexes, particularly the twisting reflexes in placing the well of Gross.

(5) Electromanometry. The intra-cardiac presstres were recorded with the Sanborn electrocardiomanometer.

\begin{tabular}{|c|c|c|}
\hline $\begin{array}{l}\text { No of dogs } \\
\text { and sessions }\end{array}$ & $\begin{array}{c}\text { No of readings } \\
\text { each }\end{array}$ & $\begin{array}{c}\text { No of } \\
\text { observations }\end{array}$ \\
\hline $\begin{array}{l}2 \\
6 \\
4 \\
2 \\
1 \\
1\end{array}$ & $\begin{array}{r}1 \\
2 \\
3 \\
4 \\
5 \\
11\end{array}$ & $\begin{array}{r}2 \\
12 \\
12 \\
8 \\
5 \\
11\end{array}$ \\
\hline 16 & & 50 \\
\hline
\end{tabular}

On the Sanborn electrocardiomanometer, the different curves of intra-cardiac pressures, auricular and ventricular, right and left, were absolutely comparable to the curve of the femoral blood pressure registered on the Ludwig manometer, and recorded on a smoked cylinder: that is, the intra-cardiac pressure decreased in 40 per cent of the cases by only $5-10 \mathrm{~mm}$. $\mathrm{Hg}$.

(6) Pulmonary ventilation (using Collin's Spirometer). In all the dogs, the intravenous injection of Pacatal ( $5 \mathrm{mg}$. $/ \mathrm{kg}$. body wt.) provoked an increase in the ventilation per minute at rest. There was an increase, either in the frequency of breathing or in the tidal air, or in both. Pacatal, therefore, did not depress the respiration This is an essential property of a good drug in pulmonary surgery.

\begin{tabular}{|c|c|c|}
\hline $\begin{array}{l}\text { No of dogs } \\
\text { and sessions }\end{array}$ & $\begin{array}{c}\text { No of readings } \\
\text { each }\end{array}$ & $\begin{array}{c}\text { No of } \\
\text { observations }\end{array}$ \\
\hline $\begin{array}{l}1 \\
9\end{array}$ & $\begin{array}{l}1 \\
2\end{array}$ & $\begin{array}{r}1 \\
18\end{array}$ \\
\hline 10 & 3 & 30 \\
\hline$\overline{20}$ & & $\overline{49}$ \\
\hline
\end{tabular}


Interestingly, a similar experiment with chlorpromazine always provoked a fall in intra-cardiac pressure on the electromanometer (11).

(7) Cardiac output (Fick). In the course of the 12 experimients on 12 different dogs, the cardiac output was measured once on each. Also, with Pacatal, the cardiac output of our dogs remained stable in 50 per cent of the cases, and we noted a slight decrease in the other 50 per cent. This latter fall was attributable to the modifications in the minute oxygen consumption.

Here again, we note that similar previous experiments with chlorpromazine have always shown a lowered cardiac output in all the cases (11).

(8) Blood constituents. Towards the end of 10 experiments on 10 different dogs a blood sample was analyzed and no notable modification was found.

(9) Sedative and potentiating effect. In all 50 dogs the sedative and potentiating effect of Pacatal was quite noticeably shown by the co-operative behaviour of the subjects. In fact, even the most distraught and ill-tempered animals complacently submitted to venoclysis for anaesthesia induction when the combination morphine-Pacatal was used as premedication. The doses of morphine were gr. 1/8 for dogs under $50 \mathrm{lb}$. and gr. $1 / 6$ for those over $50 \mathrm{lb}$., and those of Pacatal the usual $5 \mathrm{mg}$. $/ \mathrm{kg}$. body weight.

(10) Anti-oedema effect. A vain attempt to provoke acute pulmonary oedema was made on two dogs which had received Pacatal by rapidly injecting $20 \mathrm{cc}$. of hypertonic saline intravenously.

(11) Action on sympathetic and parasympathetic nervous systems. The vagolytic action of Pacatal was demonstrated by the absence of hypotension and of bradycardia after galvanic stimulation of the distal cut end of the vagus nerve. Its sympathicolytic action is shown by the inhibition of the sino-carotid reflex and by the . contraction of the nicitating membrane after galvanic stimulation of the cervical preganglionic sympathetic fibres

\section{Pacatal in Pulmonary Surgery}

We now pass on to the use of Pacatal in man, and more particularly in thoracic pulmonary surgery. Proving to be a powerful ataraxic and a well-balanced neuroplegic, Pacatal soon came into routine daily use in our thoracic surgery centre. For the last six or eight months, it has been regularly adrninistered to all our thoracic cases.

\section{Anaesthetic Technique}

The present study is based on the use of Pacatal in a hundred cases of pulmonary surgery chosen at random, and including segmentectomies, cuneiform resections, lobectomies and pneumonectomies. The average age of the pitients was 33 years, the youngest being 10 years old, and the oldest 60 . In ramote premedication, 36 to 48 hours before operation, we use Pacatal in anxious patients where the usual sedatives are inadequate to alleviate the preoperative anxiety. To these patients doses of $100 \mathrm{mg}$. are administered orally, three times a day, without side effect other than dryness of the mouth and a slight degree of consti- 
pation. In the event of too marked an effect, the dose is simply temporarily reduced. Moreover, with Pacatal, we are always successful in quieting the most anxious patients and we note here an advantage it has over chlorpromazine. With Pacatal, as it is but slightly hypotensive, it is unnecessary to keep the patients in bed.

In immediate premedication, we use Pacatal routinely on all patients, because of its neuroplegic properties; potentiation of sedatives and anaesthetics, and cardiac protection. Pacatal is then administered intramuscularly in doses of 50 to $100 \mathrm{mg}$., immediately before the operation (i.e., a half-hour before the operation time proper). If need be, in the course of anaesthesia, during long surgical operations, a supplement of Pacatal is injected intravenously at the rate of onehalf the initial dose $(25-50 \mathrm{mg}$. $)$. It is our experience that the best practical total dose of Pacatal given as premedication plus that given during operation can be satisfactorily calculated about the round figure of $1 \mathrm{mg}$./lb. body weight. (example: a $150 \mathrm{lb}$. patient may receive $100 \mathrm{mg}$. preoperatively and the remaining $50 \mathrm{mg}$. during operation). Of course, this schedule is tentative and must be adapted to the individual patient. On awakening, Pacatal is again given intravenously or intramuscularly $25 \mathrm{mg}$. at a time, to control agitation or vomiting. Finally, in the postoperative period, Pacatal is sometimes prescribed to control operative "stress" in the few excessively nervous and anxious patients. Pacatal is not an analgesic in itself and can, therefore, be prescribed in association with other sedatives.

\section{Discussion}

Following the example of Huguenard and Laborit (10), we believe that the ganglionic blockade of the neuro-vegetative system can diminish and even suppress the risks of shock caused by the stimulation of regions rich in adrenergic fibres (sympathetic, periaortic and cardiac plexuses, phrenic and splanchnic nerves) found in the thorax, and which are subjected during thoracic interventions to all sorts of aggressions. Pacatal actually provides a well-balanced ganglionic blockade in keeping equilibrium between sympathetic and parasympathetic. It ensures the heart a protection, which, though imperfect, has until now been impossible. And if we admit that parenchymatous and bronchial complications of thoracic operations often have a neuro-vegetative cause, and that a vagosympathetic disequlibrium is involved in the origin of atelectasis, we must agree that the use of a well-balanced ganglioplegic such as Pacatal would guarantee smoother postoperative periods.

From our experience with Pacatal, in more than a hundred patients undergoing pulmonary surgery, we are inclined to believe that this new phenothiazine derivative improves the peripheral circulation during operation. Pacatal diminishes capillary permeability, so that there is less operative shock and less venous stagnation, especially in the face-down position on the Overholt table. Pacatal reduces the incidence of arrhythmia during operation and, consequently, the incidence of cardiac arrest. (There were none in this series as compared to an incidence of 2 per cent of cardiac arrests in a previous unpublished study of 500 cases at this hospital). Pacatal reduces by about 10 per cent the doses of cura- 
rising agents and anaesthetics: $900 \mathrm{mg}$. of barbiturates instead of 1,000 mg. and over, for a $3 \frac{1}{2}$-hour operation. In addition to barbiturates, nitrous oxide-oygen is adminstered alone with the necessary curarising agents.

Pacatal slightly reduces bleeding during operation (an average loss of $900 \mathrm{cc}$. in our 100 pulmonary resections). This can be compared to an average blood loss of $1,500 \mathrm{cc}$. in a previous series of 119 pulmonary resetions (12). Of course, Pacatal is not the sole factor since it is highly.probable that improved surgical techniques are also contributing.

In this series not one patient developed postoperative oedema where Pacatal was used. In the previous series of 500 cases mentioned above I remember of a few patients with oedemas, some of which were caused by postoperative overloading.

In that previous series of 500 pulmonary resetions there was a 16 per cent incidence of postoperative atelectasies, whereas in this present series only 8 per cent needed bronchial aspiration.

However, as mentioned above, the lower incidence of complications in the present series, interesting as it may be in relation to Pacatal, is attributable to improved techniques as well as to the drug used.

\section{ConCLuSION}

The potentiated anaesthesia with Pacatal in cardio-pulmonary surgery certainly presents advantages, above all in regard to cardiac protection: absence or marked reduction of ventricular fibrillation in experimental cardiac surgery in dogs, and absence of arrhythmia and cardiac arrest in thoracic pulmonary surgery in man. Moreover, the 500 different studies made on dogs clearly demonstrate that Pacatal is "not a dangerous drug. Many times the effective dose of Pacatal has been injected in dogs without any toxic effect. Femoral and intra-cardiac pressures and cardiac output "are very slightly changed, as are the blood constituents. Finally, in the remote premedication for anxious subjects, Pacatal is probably the ataraxic that can be prescribed with the minimum of danger and the maximum of efficiency.

Pacatal, therefore, ensures a better preoperative sedation, a smoother induction of anaesthesia, a more effective cardiac protection, a quieter postoperative period and has a marked anti-secretory effect. For all these reasons, in our opinion, Pacatal can certainly take an enviable place in the therapeutic arsenal of the surgeon and of the thoracic anaesthetist.?

\section{ACKNOWLEDGMENTS}

I wish to express my gratitude to the surgeons of Laval Hospital and particularly to Dr. Fernando Hudon, professor of anaesthesia, for his authoritative guidance.

\footnotetext{
1Since the preparation of this work, we have used "Pacatal" on some twenty other patients in the pulmonary clinic, as well as in some fifteen other experments on dogs, and we have obtained results identical to thosereported in the above series.
} 


\section{RÉSUMÉ}

L'anesthésie potentialisée au Pacatal en chirurgie cardio-pulmonaire présente certainement des avantages, surtout en ce qui regarde la protection cardiaque: absence ou réduction marquée de la fibrillation ventriculaire en chirurgie cardiaque expérimentale chez le chien et absence d'arythmie et d'arrêt cardiaque chez l'homme en chirurgie thoracique pulmonaire.

De plus les 500 études différentes faites chez le chien démontrent clairement que le Pacatal n'est pas un médicament dangereux; chez le chien, la dose utile de Pacatal a été plusieurs fois injectée sans effets mocifs.

Les pressions artérielles fémorales et intracardiaques, le débit cardiaque sont peu modifiés, et il en est de même de la formule sanguine. Enfin, cliniquement, en prémédication éloignée chez anxieux, le Pacatal est probablement l'ataraxique qu'on peut prescrire avec le minimum de danger et le maximum d'efficacité. Voilà pourquoi, à notre avis, le Pacatal peut certamement prendre une place enviable dans l'arsenal thérapeutique du chururgien et de l'anesthésiste thoracique.

\section{REFERENCES}

1 Nieschulz, O., Popendiker, K, \& Sock, K Arzneim-Forsch 4232 (1954)

2 Donat, Kraus On the Prevention of Disturbances of the Cardiac Rhythm in Operations Der Anaesthetist 4(3): 65 (1955)

3 Gaderman, E, \& Donat, $K$ Influence Exerted on Irritability of the Heart in the Course of Anesthesia Klin Wchnschr 32713 (Aug 15, 1954)

4 Horatz, K. The Narcosis in Operations of the Bloodless Heart Tr 20th Internat Coll Surgeons, Geneva, p 518 (1955).

5. Horatz, K. Controlled Hypotension in Surgery Proc World Cong. Anesthesiologists, p 136 (1955). Edited by Internat Anesth Res Sac

6. Davies, John I., Huggins, D. H M, \& Wolkenstexn, C F Pacatal in Anesthesia A Preliminary Report. Canad Anaesth Soc J, 3(3) 224 (1956)

7. Jores, A. Clinic and Polyclinic at the University of Hamburis-Eppendorf

8 Pedersen, S Anesthesia and Stress. Proc World Cong Anesthesiologists, p. 17 (1955). Edited by Internat. Anesth Soc.

9. Warner-Lambert International Pacatal Literature Survey

10 Huguenard, P., \& Laborut, H Pratique de l'hibernothérapie en chirurgie et en en médecine. Parıs, Masson (1954)

11 DechêNe, J-P, Hudon, F, \& Graver, J-A Hypotherme et chrurgie intracardiaque expérimentale Laval méd 21(3) (mars 1956)

12 Hudon, F, \& Dechêne, J.-P. Contribution de l'anesthésıe à la chrurgie thoracique en tuberculose Laval méd. 18(4) (avr1 1953) 